\title{
Severe post-traumatic disorder leading to failure of passing asylum interview-a case report
}

\author{
Ashish Sarangi ${ }^{*}$ (D), Sabrina Deleon, Regina Baronia, Rosalinda Jimenez and Yasin Ibrahim
}

\begin{abstract}
Background: Asylum applicants can benefit from psychiatric evaluation which can explain how culture and mental health symptoms relate to perceived deficits in credibility.

Case presentation: Ms. B presented for psychiatric evaluation, seeking asylum in the USA after multiple threats on her life in Honduras. At initial evaluation, she was diagnosed with depression. On reevaluation, she was found to have panic attacks and post-traumatic stress disorder. Recommendations included an anxiolytic medication and the use of pre-written statements upon interview. However, Ms. B was sent back to her country of origin despite her severe mental symptoms.

Conclusion: Post-traumatic disorder scales should be used by mental health professionals especially with patients who are not forthcoming about past trauma history to avoid missing this diagnosis. There is a need to inform immigration officials and lawyers about the necessity of accommodating clients' needs to appropriately present themselves in asylum interviews.
\end{abstract}

Keywords: Asylum, Detention, Panic attacks, Mental health, Accommodations, PTSD

\section{Background}

Asylum applicants can benefit from a professional psychiatric evaluation prior to court appearance. The evaluation explains how culture and mental health symptoms relate to perceived deficits in credibility [1]. High prevalence of depression generalized anxiety disorder, and posttraumatic stress disorder among the vulnerable population of asylum seekers and refugees have been observed. In a study conducted by Physicians for human rights, posttraumatic symptoms risk and prevalence were significantly higher among asylum seekers [2]. In the Fazel et al. (2012) systematic review "Refugees resettled in western countries could be about ten times more likely to have posttraumatic stress disorder than age-matched general populations in those countries" [3]. Many asylum applicants have undergone multiple traumatic events and being able

\footnotetext{
* Correspondence: aks_sarangi@hotmail.com

Texas Tech University Health Sciences Center, 3601 4th St., Lubbock, TX, USA
}

to process the events as well as elicit specifics from those events is a difficult undertaking without support or professional help. A psychiatric evaluator can also advise "attorneys in the preparation of clients for the stressful process of testifying for asylum" [1]. Professional evaluations can allow the applicants to strengthen their case for asylum through providing an official assessment as well as recommendations for future treatment.

\section{Case presentation}

Ms. B a woman in her twenties presented in the USA seeking asylum after receiving multiple threats from a prominent international gang based in Honduras. Ms. B, a vocal supporter of the national party described two events of direct death threats from members of the gang. During one of the events, she was told, "be careful, we are watching you and we will kill you." During review of symptoms, the patient disclosed poor appetite and poor sleep with frequent nightmares of being killed since the
Springer Open

(c) The Author(s). 2021 Open Access This article is licensed under a Creative Commons Attribution 4.0 International License, which permits use, sharing, adaptation, distribution and reproduction in any medium or format, as long as you give appropriate credit to the original author(s) and the source, provide a link to the Creative Commons licence, and indicate if changes were made. The images or other third party material in this article are included in the article's Creative Commons licence, unless indicated otherwise in a credit line to the material. If material is not included in the article's Creative Commons licence and your intended use is not permitted by statutory regulation or exceeds the permitted use, you will need to obtain permission directly from the copyright holder. To view a copy of this licence, visit http://creativecommons.org/licenses/by/4.0/. 
incident. Mental status exam was significant for hesitancy to respond to questions that would evoke her emotional pain. the subject required frequent encouragement to complete the interview. The patient was diagnosed with depression, and the fear of deportation appeared credible. After the initial psychiatric evaluation, the patient was interviewed by an asylum officer and was unable to respond to questions regarding her trauma. Ms. B's asylum application was unsuccessful, and the decision was appealed with a request for reevaluation by her legal counsel. This appeal was based on Ms. B's significant history of physical and emotional trauma from her son's father that was not mentioned in the first evaluation.". Ms. B's lawyer informed the evaluation team that Ms. B had a significant history of physical and emotional trauma from her son's father who was not mentioned during the first evaluation.

During the second evaluation, the patient reported that during her interview with the asylum officer "I had the answers in my mind, but I could not speak, I was so stressed out because it was about my life. He (the asylum officer) did not give me enough time to respond and would jump to the next question before I start to speak." When prompted to share the history of physical and emotional trauma, she endured from her ex-partner she was unable to speak and visibly tearful. The patient was then asked to share in writing her past trauma and she was able to give details about repeated physical and emotional abuse, including throwing hot water on her leg and pulling her hair. After re-evaluation by the psychiatrist, Ms. B was diagnosed with panic attacks secondary to post-traumatic disorder (PTSD) and recommended to receive an anxiolytic prior to the next asylum interview as well as accommodations to read pre-written statements and to respond to questions in writing if unable to speak. Recommendations were made for Ms. B to be given an anxiolytic prior to the next interview and be allowed more time by the asylum evaluators to respond to questions Upon the second interview with the asylum officer, it was unknown if the recommended accommodations were followed. However, Ms. B, in the end, was deported to her country of origin, despite her severe psychiatric symptoms.

\section{Discussion}

Ms. B's prior domestic trauma predisposed her to developing post-traumatic symptom disorder (PTSD) once the gang death threats, a predisposing factor, occurred. She met the most important criteria for PTSD which is an actual threat to her physical safety. The threat was persistent for many years. She also demonstrated significant avoidance and negative cognition in her mood in support of the diagnosis of PTSD as evidence by her limited answers and hesitancy to elaborate to questions posed to her by the asylum officer.

Malingering defined as intentionally producing false or grossly exaggerated physical or psychological symptoms [4] although always a possibility was low on our differential list as the patient did not show any evidence of exaggerating her symptoms and we did not suspect embellishment. The patient also reported significant nightmares and hyperarousal requiring us to make a recommendation for an anxiolytic. The hyperarousal in PTSD is often associated with panic attacks characterized by chest pain, palpitations, shortness of breath and a "sense of impending doom." When obtaining the psychiatric evaluation with an unknown history, symptoms of avoidance can mask the traumatic exposure which in this case was prior physical and emotional abuse [2]. Patients often avoid revisiting details of their trauma out of fear of repeated panic attacks. "Persistent avoidance of stimuli associated with the traumatic event(s) or negative alterations in cognitions and mood associated with the traumatic event" is another criterion of diagnosis per DSM-5." When the subject is unable to recount the traumatic event history as a form of avoidance, and there are no collateral sources of information, proper diagnosis is difficult as this is solely dependent on the subject's recounting of events and ability to verbalize her symptoms. This is especially true when there is no collateral available from another historian. Suppression of prior traumatic memories is often seen in patients with PTSD and in chronic cases smaller volume and size of bilateral hippocampi is noted in this patient population [5]. In Ms. B's case, the lack of collateral information and significant avoidance in the retelling of her history during the asylum evaluation resulted in overlooking a diagnosis of PTSD.

Due to severe deficiency of trained mental health providers and high volume of asylum-seekers, providers may not choose to administer trauma scales, which may lead to less accurate psychological assessment [6]. This was the case with Ms. B, for the sake of evaluating more clients; we skipped administration of PTSD scales. Hence, we initially misdiagnosed her with depression which is not an uncommon mistake [7].

In evaluating such patients, where no other informants are available to provide a history of trauma, it is crucial to whenever available; administer scales, such as The Harvard Trauma Questionnaire (HTQ). The HTQ's "cultural sensitivity may make it useful for assessing other highly traumatized non-Western populations" [8]. The Grasso et al. study found that, "multiple informants and multiple measures improve accuracy when assessing," and a, "knowledge of past traumatic events is a prerequisite for the survey of PTSD symptoms" [9].

Exposure to trauma is hypothesized to be an etiological factor in the emergence of panic disorder, which 
has a prevalence of about 35\% in patients with PTSD. In those patients, panic attacks can be triggered by reminders of trauma [10].

In the case of Ms. B, the necessary questioning for asylum evaluation may have precipitated her panic attacks and hindered her ability to properly respond to the asylum officer's interview.

The management and evaluation of asylum applicants by US Immigration and Customs Enforcement (ICE) detention centers follow the 2011 Operations Manual ICE Performance-Based National Detention Standards (PBNDS) [11]. According to this manual, a comprehensive physical examination, as well as a mental health screening by a mental health care professional, is required within 14 days of admission to an ICE detention center [11]. Thus, there is a need for a timely and accurate diagnosis and recommendations by the evaluating psychiatrist.

The asylum application of Ms. B was unsuccessful. However, there are several objectives that can be gleaned from her case. In the authors' opinion, an accurate and timely diagnosis is essential to assist asylum officers in their own independent investigation of the case in hand. Secondly, mental health professionals should be allowed to convey their independent recommendations to the asylum officers. This may also be beneficial to the officers to rule out cases of malingering which is a credible concern. Mental health professionals in return should be aware of the legal code and evaluation provisions for asylum seekers. Ethical considerations include interview confidentiality and the need to disclose certain sensitive topics obtained during the psychiatric evaluation to asylum officers. If the asylum application is unsuccessful, consideration may be given to the asylum seekers to obtain another independent psychiatric evaluation to appeal their case.

\section{Conclusion}

Post-Traumatic Stress Disorder is one of the psychiatric disorders that persons seeking asylum often present with to the USA. The source of this trauma is often gangrelated violence and riots in the patient's country of origin. Patients with PTSD often have comorbid panic attacks which leads to avoiding reminders of their trauma due to a fear of repeated panic attacks. The avoidance symptoms of PTSD in this population can pose a challenge in obtaining accurate history of trauma and hinder their ability to gain asylum rightfully. Hence, administration of PTSD scales can be a crucial tool in identifying the correct diagnosis particularly in asylum seekers who are not forthcoming. In addition, asylum officials should be reminded and encouraged to offer the appropriate accommodations to asylum seekers with mental health disorders.

\section{Abbreviations}

PTSD: Post-traumatic stress disorder; HTQ: The Harvard Trauma

Questionnaire; PBNDS: Performance-Based National Detention Standards

\section{Acknowledgements}

We would like to thank Dr. Sarah Wakefield Department Chair at Texas Tech University Health Sciences Center for her idea behind the manuscript development.

\section{Authors' contributions}

SD and AS both contributed to Introduction and Abstract sections. RB and YI contributed to Discussion and Conclusion sections. RJ contributed to title and case presentation sections. All authors have read and approved the manuscript.

\section{Funding}

No funding obtained.

\section{Availability of data and materials}

Not applicable.

\section{Declarations}

Ethics approval and consent to participate

Full consent was obtained prior to submission from patient.

\section{Consent for publication}

Written informed consent to publish this information was obtained the study participant.

\section{Competing interests}

The authors declared that they have no competing interest.

Received: 27 February 2021 Accepted: 15 March 2021

Published online: 03 May 2021

\section{References}

1. Lustig SL, Kureshi S, Delucchi KL, lacopino V, Morse SC (2008) Asylum grant rates following medical evaluations of maltreatment among political asylum applicants in the United States. J Immigr Minor Health 10(1):7-15. https:// doi.org/10.1007/s10903-007-9056-8

2. Meltzer EC, Averbuch T, Samet JH, Saitz R, Jabbar K, Lloyd-Travaglini C, Liebschutz JM (2012) Discrepancy in diagnosis and treatment of posttraumatic stress disorder (PTSD): treatment for the wrong reason. J Behav Health Serv Res 39(2):190-201. https://doi.org/10.1007/s11414-011-9263-x

3. Kostaras P, Bergiannaki J-D, Psarros C, Ploumbidis D, Papageorgiou C (2016) Posttraumatic stress disorder in outpatients with depression: still a missed diagnosis. J Trauma Dissociation 18(2):233-247. https://doi.org/10.1080/152 99732.2016.1237402

4. Bass C, Wade DT (2019) Malingering and factitious disorder. Pract Neurol 19(2):96-105. https://doi.org/10.1136/practneurol-2018-001950 Epub 2018 Nov 13. PMID: 30425128

5. Logue MW, van Rooij SJH, Dennis EL, Davis SL, Hayes JP, Stevens JS, Densmore M, Haswell CC, Ipser J, Koch SBJ, Korgaonkar M, Lebois LAM, Peverill M, Baker JT, Boedhoe PSW, Frijling JL, Gruber SA, Harpaz-Rotem I, Jahanshad N, Koopowitz S, Levy I, Nawijn L, O'Connor L, Olff M, Salat DH, Sheridan MA, Spielberg JM, van Zuiden M, Winternitz SR, Wolff JD, Wolf EJ, Wang X, Wrocklage K, Abdallah CG, Bryant RA, Geuze E, Jovanovic T, Kaufman ML, King AP, Krystal JH, Lagopoulos J, Bennett M, Lanius R, Liberzon I, McGlinchey RE, McLaughlin KA, Milberg WP, Miller MW, Ressler KJ, Veltman DJ, Stein DJ, Thomaes K, Thompson PM, Morey RA (2018) Smaller hippocampal volume in posttraumatic stress disorder: a multisite ENIGMA-PGC study: subcortical volumetry results from posttraumatic stress disorder consortia. Biol Psychiatry 83(3):244-253. https://doi.org/10.1016/j. biopsych.2017.09.006

6. Grasso D, Boonsiri J, Lipschitz D, Guyer A, Houshyar S, Douglas-Palumberi H, Massey J, Kaufman J (2009) Posttraumatic stress disorder: the missed diagnosis. Child Welfare 88(4):157-176

7. Cloitre M, Stolbach BC, Herman JL, van der Kolk B, Pynoos R, Wang J et al (2009) A developmental approach to complex PTSD: childhood and adult 
cumulative trauma as predictors of symptom complexity. J Trauma Stress 22(5):399-408. https://doi.org/10.1002/jts.20444

8. Ferdowsian H, Mckenzie K, Zeidan A (2019) Asylum medicine: standard and best practices. Health Hum Rights J 21(1):215-225

9. Cougle JR, Feldner MT, Keough ME, Hawkins KA, Fitch KE (2010) Comorbid panic attacks among individuals with posttraumatic stress disorder: associations with traumatic event exposure history, symptoms, and impairment. J Anxiety Disord 24(2):183-188

10. Hinton DE, Hofmann SG, Pitman RK, Pollack MH, Barlow DH (2008) The panic attack-posttraumatic stress disorder model: applicability to orthostatic panic among Cambodian refugees. Cogn Behav Ther 37(2):101-116

11. Granski M, Keller A, Venters H (2015) Death rates among detained immigrants in the United States. Int J Environ Res Public Health 12(11): 14414-14419. https://doi.org/10.3390/ijerph121114414

\section{Publisher's Note}

Springer Nature remains neutral with regard to jurisdictional claims in published maps and institutional affiliations.

\section{Submit your manuscript to a SpringerOpen ${ }^{\circ}$ journal and benefit from:}

- Convenient online submission

- Rigorous peer review

- Open access: articles freely available online

- High visibility within the field

- Retaining the copyright to your article

Submit your next manuscript at $\boldsymbol{\wedge}$ springeropen.com 